\title{
OTOLOGY
}

\section{Radiologic measurement of cochlea and hearing preservation rate using slim straight electrode (Cl422) and round window approach}

\author{
Misurazione radiologica della coclea e tasso di preservazione uditiva utilizzando \\ elettrodo sottile a punta dritta (Cl422) e approccio alla finestra rotonda

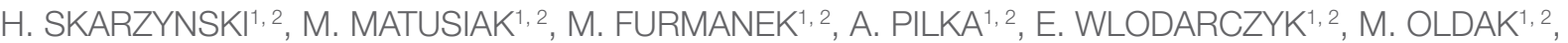 \\ P.H. SKARZYNSKI ${ }^{1,2,3,4}$ \\ ${ }^{1}$ Institute of Physiology and Pathology of Hearing, Mochnackiego, Warsaw, Poland; ${ }^{2}$ World Hearing Center, \\ Mokra, Kajetany, Poland; ${ }^{3}$ Department of Heart Failure and Cardiac Rehabilitation, Medical University of Warsaw, \\ Kondratowicza, Warszawa, Poland; ${ }^{4}$ Institute of Sensory Organs, Mokra, Kajetany, Poland
}

\begin{abstract}
SUMMARY
Hearing preservation surgery constitutes a considerable branch of cochlear implantation surgery and is being steadily developed and perfected. The aim of the study was to verify if insertion of a cochlear implant electrode according to individually calculated linear insertion depth improves hearing preservation. We evaluated the relations between the size of a cochlea, insertion depth angle, linear insertion depth and hearing preservation rate (HP) according to Hearing Preservation Classification in a retrospective case review of 54 patients implanted with a slim straight electrode Nucleus CI422 in 2008-2011. Group HP was 0.75 at activation, 0.67 at 12 months (for 53 patients) and 0.60 at 24 months. In 53 cases, the mean insertion depth angle was $375^{\circ}$ (SD 17 $)$; mean calculated cochlear duct length 35.87 mm (SD 1.95); mean calculated linear insertion depth $23.14 \mathrm{~mm}$ (SD 1.68). There was no significantly relevant relation between HP values and angular insertion depth or insertion depth. Preoperative measurements of cochlea and specific parameters such as linear insertion depth have no effect on hearing preservation. Poor hearing preservation in some deep insertion cases cannot be explained entirely by the electrode position.
\end{abstract}

KEY WORDS: Cochlear implant • Electrode insertion depth $\bullet$ Hearing preservation $\bullet$ Partial deafness $\bullet$ Round window

\section{RIASSUNTO}

La chirurgia per la preservazione dell'udito costituisce oggi un'importante branca dell'implantologia cocleare e deve essere ancora sviluppata e perfezionata. L'obiettivo di questo studio è stato quello di verificare se l'inserimento dell'elettrodo dell'impianto cocleare, eseguito secondo l'angolo di inserimento calcolato individualmente, migliorasse la preservazione uditiva. In questo studio retrospettivo comprendente 54 pazienti impiantati con un elettrodo sottile a punta dritta Nucleus CI422 tra il 2008 e il 2011, abbiamo valutato la relazione tra la grandezza della coclea, l'angolo di inserimento e il tasso di preservazione uditiva (HP) in accordo con la Hearing Preservation Classification. Il tasso di preservazione uditiva è stato pari a 0,75 all'attivazione, 0,67 a 12 mesi (per 53 pazienti) e 0,60 a 24 mesi. Nei 53 pazienti l'angolo di inserimento medio è stato pari a $375^{\circ}\left(S D 17^{\circ}\right)$; la lunghezza media del condotto cocleare è risultata pari a 35,87 mm (SD 1,95); la profondità di inserimento pari a $23,14 \mathrm{~mm}(S D$ 1,68). Non è stata rilevata alcuna differenza statisticamente significativa tra $i$ valori di HP e l'angolo di inserimento o la profondità di inserimento. La misura preoperatoria della coclea e di parametri specifici quale la profondità di inserimento non hanno effetto sulla preservazione uditiva. Bassi valori di preservazione uditiva in alcuni casi di inserimento profondo non possono essere spiegati solamente dalla posizione dell'elettrodo.

PAROLE CHIAVE: Impianto cocleare $\bullet$ Profondità di inserimento dell'elettrodo $\bullet$ Preservazione uditiva $\bullet$ Finestra rotonda $\bullet$ Sordità parziale

Cite this article as: Acta Otorhinolaryngol Ital 2018;38:468-475. http://dx.doi.org/10.14639/0392-100X-1579

(C) Società Italiana di Otorinolaringologia e Chirurgia Cervico-Facciale

\section{Introduction}

Hearing preservation surgery constitutes a considerable branch of cochlear implantation surgery and is being steadily developed and perfected ${ }^{12}$. There is much dis- cussion about the terminology and groups of patients, as different authors apply different definitions to terms such as residual hearing or deep insertion.

A crucial aim of cochlear implantation, apart from deliver- 
ing electric stimulation to non-functioning parts of cochlea, is to preserve low frequency preoperative hearing after surgery ${ }^{3}$. The degree of intracochlear mechanical trauma caused by surgical intervention may range from minor vascular injury, tearing of a spiral ligament, displacement or perforation of basilar membrane to fracturing of osseous spiral lamina or modiolar wall; it is associated with an acute inflammatory response ${ }^{45}$. The cause of these problems may be not only the fault of the surgical technique and surgeon's inexperience, but may also be related to the individual anatomy of cochlea and physical parameters of electrode array and how they relate to each other. Many researchers have studied the issue of the depth of insertion of an electrode array as there is a trade-off between the expected cochlear coverage and risk of direct physical trauma caused by electrode's presence ${ }^{4-9}$.

When analysing the placement of an electrode array of a specific length ${ }^{10}{ }^{11}$, we cannot use either angular insertion depth or linear insertion as a measure of cochlear duct coverage with relation to its tonotopic organisation because of large inter-individual variability of cochlea measurements ${ }^{812-15}$. Additionally, several studies have shown that penetration of an electrode array into apical functioning parts of cochlea may considerably increase the risk of hearing deterioration or loss ${ }^{16-18}$. In this context, a question arises if we could use precise estimation of an individual array insertion depth in relation to the expected frequency along the organ of Corti as a tool for optimising outcomes of hearing preservation. In other words, can measuring a cochlea before surgery be helpful in increasing hearing preservation rate in cochlear implantation?

Several papers have been published investigating the relationship between depth of electrode array insertion and residual hearing preservation in cochlear implantation. There is an inherent limitation to the learning value of these reports because each relates the results obtained with different array types, different surgical approaches to cochlea, different methods of estimating the array position and, what of crucial importance, in the face of lack of a uniform classification system of hearing preservation have used various evaluation methods, and thus the results are difficult to compare ${ }^{45}{ }^{17-19}$. Fraysse et al. ${ }^{18}$ presented the results of 21 adult patients implanted with a perimodiolar electrode through cochleostomy. They found no significant relationship between preservation of hearing and insertion depth angle. However, they reported considerable hearing loss in cases of deeper insertions, i.e. in smaller cochleae. Similar results have been reported by James et al. ${ }^{17}$ in their study with a perimodiolar array implanted through a cochleostomy approach. Erixson et al. ${ }^{19}$ studied two MedEl electrodes of different lengths, flex EAS (now Flex24) and flex soft, and found no significant relation between angular insertion depth and hearing preservation rate, although the two deepest insertions resulted in complete hearing loss. Causon et al. ${ }^{5}$ in a recent literature review analysis of reported factors found a significant relation between hearing preservation and angular insertion depth, but included several different methods of hearing preservation assessment, surgical methods and approaches, electrode arrays and physical parameters. Hassepas et al. ${ }^{4}$ reported the results of 41 adults implanted with a Nucleus CI422 slim straight electrode using cochleostomy and round window technique. They focused on comparison of these two approaches in terms of insertion depths and possible scalar dislocation of array for straight electrode.

The present study is the first comprehensive approach to evaluate the relationship between the size of a cochlea, insertion depth angle and linear insertion depth and preservation of hearing assessed using the new Hearing Preservation Classification ${ }^{20}$. Study material includes the largest group of patients to date implanted with the slim straight electrode using the round window technique ${ }^{21}$. Among these patients, there were both children and adults with various degrees of low frequency hearing who had been implanted with a CI422 electrode using only two intraoperatively estimated insertion depths: $20 \mathrm{~mm}$ and $25 \mathrm{~mm}$. There was no data on cochlea measurements prior to surgery. The objective of the study was to assess if insertions performed according to the patient's specific calculated linear insertion depth increases the rate of hearing preservation.

\section{Materials and methods}

\section{Subjects}

In this retrospective analysis we analysed a group of 54 patients who underwent cochlear implantation with the Nucleus CI422 slim straight electrode in our clinic between March 2008 and January 2011. Patients with structural malformations of a cochlea, retrocochlear origin of hearing loss or aetiology suggesting obliteration or ossification were excluded.

The study received the approval of the institutional bioethics committee according to Polish legal regulations (approval number IFPS/KB/04-2009). Procedures and data collection conformed with ISO 14155:2003. The study followed the principles of the Declaration of Helsinki.

\section{Audiometric testing}

Pure tone audiometry (PTA) tests were performed using calibrated audiometers with outputs of $90 \mathrm{~dB} \mathrm{HL}$ at $125 \mathrm{~Hz}, 105 \mathrm{~dB} \mathrm{HL}$ at $250 \mathrm{~Hz}, 110 \mathrm{~dB} \mathrm{HL}$ at $500 \mathrm{~Hz}$, 
$120 \mathrm{~dB} H L$ at $1 \mathrm{kHz}, 120 \mathrm{~dB} \mathrm{HL}$ at $2 \mathrm{kHz}$, and $115 \mathrm{~dB} \mathrm{HL}$ at $4 \mathrm{kHz}$ and $6 \mathrm{kHz}$. In unaided conditions, tests were performed in a double-walled sound booth using earphones. PTA using tones in the range $0.125-6 \mathrm{kHz}$ was performed preoperatively and at 1, 5, 9, 12 and 24 months after activation of the speech processor. Hearing threshold evaluation in PTA was performed following the modified Hughson \& Westlake procedure with $5 \mathrm{~dB}$ precision ${ }^{22}$. Pre- and post-operative hearing levels were categorised according to Skarzynski's definitions ${ }^{16}$.

\section{Surgery and electrode array}

Cochlear implantation was performed in the worse hearing ear in all patients. Surgery was performed using the 6-step Skarzynski procedure with a round window approach for partial treatment of deafness. All patients received the CI422 electrode, which is a $25 \mathrm{~mm}$ slim straight electrode with 22 half band contacts and diameters $0.3 \mathrm{~mm}$ at the tip and $0.6 \mathrm{~mm}$ at proximal end. It has two white markers, at 20 and $25 \mathrm{~mm}$, to facilitate intraoperative estimation of insertion depth ${ }^{1621}$. The decision as to how deeply an electrode should be inserted was made on the basis of the PDT classification ${ }^{16}$, but if there is any resistance, force or lock during the insertion then it should be stopped. Otherwise, there is a risk that hearing will not be preserved. Steroids were administered according to our routine procedure in all patients: $0.1 \mathrm{mg} / \mathrm{kg} / \mathrm{day}$ dexamethasone IV infusion in two doses per day for 3-4 days. Questionnaires with intraoperative reports on insertion depth estimation ( $1^{\text {st }}$ marker, between markers, around $22 \mathrm{~mm}, 2^{\text {nd }}$ marker) were collected.

\section{Radiologic evaluation}

A flat-panel high-resolution computed tomography (HRCT, Somatom Definition AS, work station Siemens MMWP) was used for imaging.

\section{Diameter of the basal turn of cochlea $-A$}

Reconstructions of the cochlea image ("cochlear view") were prepared according to the method described by Xu et al. ${ }^{23}$. The $0^{\circ}$ reference angle was defined according to the coordinate system proposed by a consensus panel ${ }^{24}$. The diameter of basal turn - linear measurement $\mathrm{A}$ - was evaluated according to the method described by Cohen et al. as the largest distance from the round window through the centre of a modiolus to the opposite lateral wall of a basal turn ${ }^{25}$.

\section{Angular insertion depth}

The angle of insertion $\theta$ measured along the lateral wall of cochlea was specified and estimated according to the method described by Cohen et al. ${ }^{25}$. It is an angle between the line passing through the round window and the center of modiolus and the line connecting a specific position along the lateral wall of cochlea indicated by the electrode tip and the centre of the modiolus.

Linear insertion depth for slim straight electrode CI 422 A line tracing the outer wall of cochlea was described using the equation given by Escude ${ }^{14}$.

$\mathrm{L}=2.62 \mathrm{Ax} \log \mathrm{e}(1.0+\theta / 235)$ (Equation 1), where: $\log \mathrm{e}=$ natural $\log$ arithm; $\theta=$ angle between a line connecting the middle of a modiolus with a tip of an electrode and a line connecting the middle of a modiolus with a round window niche (lateral lip of sinus tympani) (Fig. 1).

According to method proposed by Alexiades ${ }^{26}$, in order to evaluate the linear insertion depth for a particular straight array with greater precision one should allow for the length of displacement from the outer wall towards the organ of Corti. Alexiades proposed that linear measurement A should be reduced by the doubled electrode's average radius. For CI422, the average radius is $0.45 \mathrm{~mm}$ (range 0.3-0.6). Performing appropriate substitution to Equation 1 we obtain Equation 2 as follows:

LCI422 = $2.62(\mathrm{~A}-0.9) \times \log \mathrm{e}(1.0+\theta / 235)($ Equation 2$)$.

Cochlear duct length for CI 422 electrode

For cochlear duct length (CDL), we used the same evaluation method proposed by Alexiades ${ }^{26}$.

CDLlw $=4.16 \mathrm{~A}+0.18$ (Equation 3). For CI 422 electrode the above equation is: CDLCI422 $=4.16(\mathrm{~A}$ $0.9)+0.18=4.16 \mathrm{~A}-3.54$ (Equation 4).

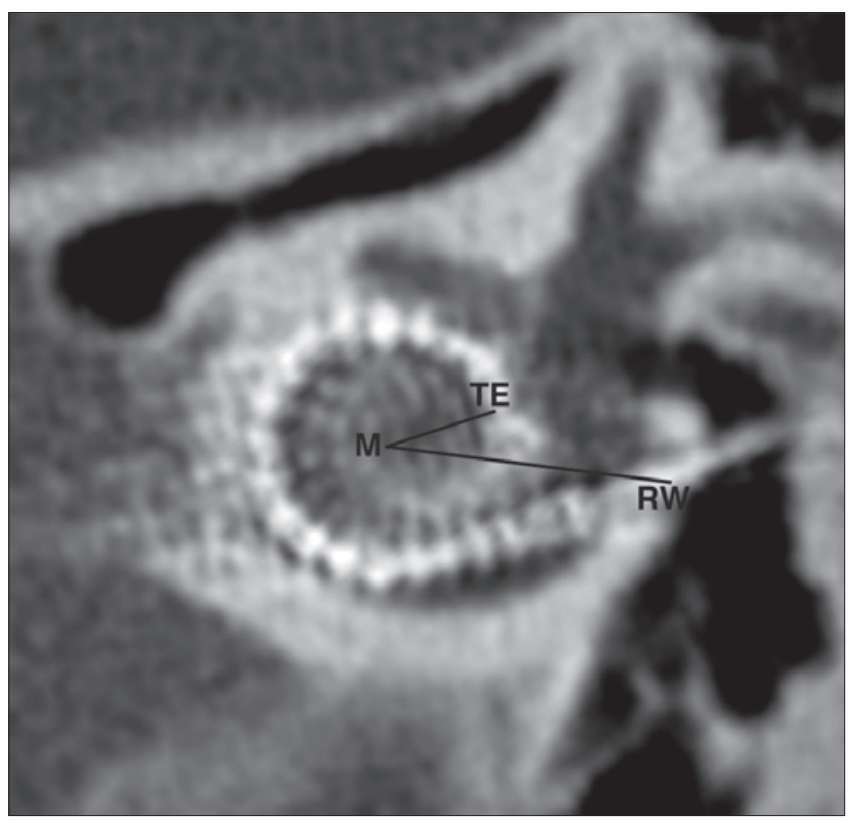

Fig. 1. CT reconstruction of cochlear view according to Xu et al. ${ }^{23}$. Angle of insertion $\theta$ estimated according to Escude. 


\section{Hearing preservation}

Hearing preservation (HP) was calculated using the new Hearing Preservation classification system proposed by Skarzynski et al. ${ }^{20}$, which is based on preoperative and postoperative PTA

$\mathrm{S}(\%)=[1-\{($ PTApost - PTApre $) /$ (PTAmax - PTApre) $\}$ x 100], where: $\mathrm{S}$ is the hearing preservation, PTApost is the pure tone average postoperatively, PTApre is the pure tone average preoperatively and PTAmax is the limit of the audiometer.

\section{Statistical analysis}

Statistical analysis was performed using Statistica 10. HP analysis for implanted and non-implanted ears was performed using a non-parametric Friedman ANOVA test and the Kendall compliance coefficient. The relation between HP rate and angular insertion depth was estimated using Pearson's linear correlation. For both tests a significance level of $\mathrm{p}<0.05$ was adopted.

\section{Results}

\section{Demographic data}

Subjects were 54 patients aged 6 to 83 years, mean 30.05 , with various degrees of high frequency sensorineural hearing loss. In this group, 26 patients were male. In 29 cases the right ear was implanted. Duration of the period of severe to profound hearing loss in study subjects ranged from 3 to 48 years, mean 13.2 (SD 2.9). In 29\% subjects hearing loss had a confirmed genetic aetiology, in $60 \%$ the aetiology was unknown, in $3 \%$ deafness was caused by peri-delivery complications, in $3 \%$ due to ototoxic drug use, in $3 \%$ was post inflammatory processes and in $2 \%$ deafness was a result of birth paralysis.

\section{Surgery}

All implantations were successfully performed by the same surgeon. Insertion was rated as easy (very little force inside cochlea, but no problem with insertion) in 15 cases, very easy (no forces or any resistance in the cochlea) in 31 cases, acceptable (because of slight force there was slower insertion, but full depth was achieved) in 6 cases and difficult in 2 cases. Intraoperative estimation of insertion depth was as follows: in 29 cases $2^{\text {nd }}$ marker, between $1^{\text {st }}$ and $2^{\text {nd }} 2$ cases, and in 23 cases $1^{\text {st }}$ marker.

\section{Hearing preservation}

In all subjects but one the PTA hearing thresholds were measured across frequencies preoperatively and over the 24-month follow-up period. One patient had temporarily fallen out of follow-up, and thus HP at 12 months was calculated for only 53 subjects. For the entire group analysed, the S value of HP was calculated and was 0.75 at activation, 0.67 at 12 months and 0.60 at 24 months.

\section{Radiologic evaluation}

\section{Angular insertion depth $\theta$}

In all cases but one reconstructions of cochlea images were successfully obtained in the early postoperative period (Fig. 1). The image quality of the excluded patient was insufficient to obtain cochlear view reconstruction. The measured insertion depth angles of array ranged from $310^{\circ}$ to $540^{\circ}$, mean $375^{\circ}\left(\operatorname{SD~} 17^{\circ}\right)$.

Cochlear duct length for CI422 electrode - CDLCI422 Calculated cochlear duct length for the CI422 electrode ranged from $30.16 \mathrm{~mm}$ to $40.56 \mathrm{~mm}$, mean $35.87 \mathrm{~mm}$ (SD 1.95).

\section{Linear insertion depth for CI422 electrode - LCI422}

Calculated linear insertion depth of the CI422 electrode array in postoperative reconstructions of cochlear view ranged from $19.81 \mathrm{~mm}$ to $26.43 \mathrm{~mm}$, mean $23.14 \mathrm{~mm}$ (SD 1.68).

Relationship between individual $\mathrm{S}$ values of HP in the studied group at activation, 12 and 24 months of followup and the individual angular insertion depths $\theta$ was evaluated, and no statistically significant relation was found (respectively $\mathrm{p}=0.1, \mathrm{p}=0.2, \mathrm{p}=0.1$ ) (Fig. 2).

Likewise, the relation between the $\mathrm{S}$ value of HP for each subject in the group and intra-operatively estimated depth of insertion did not show any statistical significance (Fig. 3).

\section{Discussion}

Individual variability of cochlea size (Stakchovskaya ${ }^{12}$ in the study of temporal bone specimens reports a $6.37 \mathrm{~mm}$ difference between the shortest and the longest cochlear duct in her material) and a large variety of residual hearing levels are the two factors that have to be considered when attempting to determine the relationship between preservation of hearing and array insertion depth ${ }^{12}$. In the relations analysed in our study, we assumed two different conditions of implantation. The first is that a surgeon does not know the cochlea size preoperatively, and the only available information is hearing status and electrode length. Secondly, a surgeon knows the diameter of the basal turn, and can thus calculate cochlear duct length, and also knows hearing status and electrode length ${ }^{26}$. However, due to anatomical variations of cochlea dimensions the angle of insertion does not provide an actual data on frequency coverage, because in a large cochlea, as for ex- 


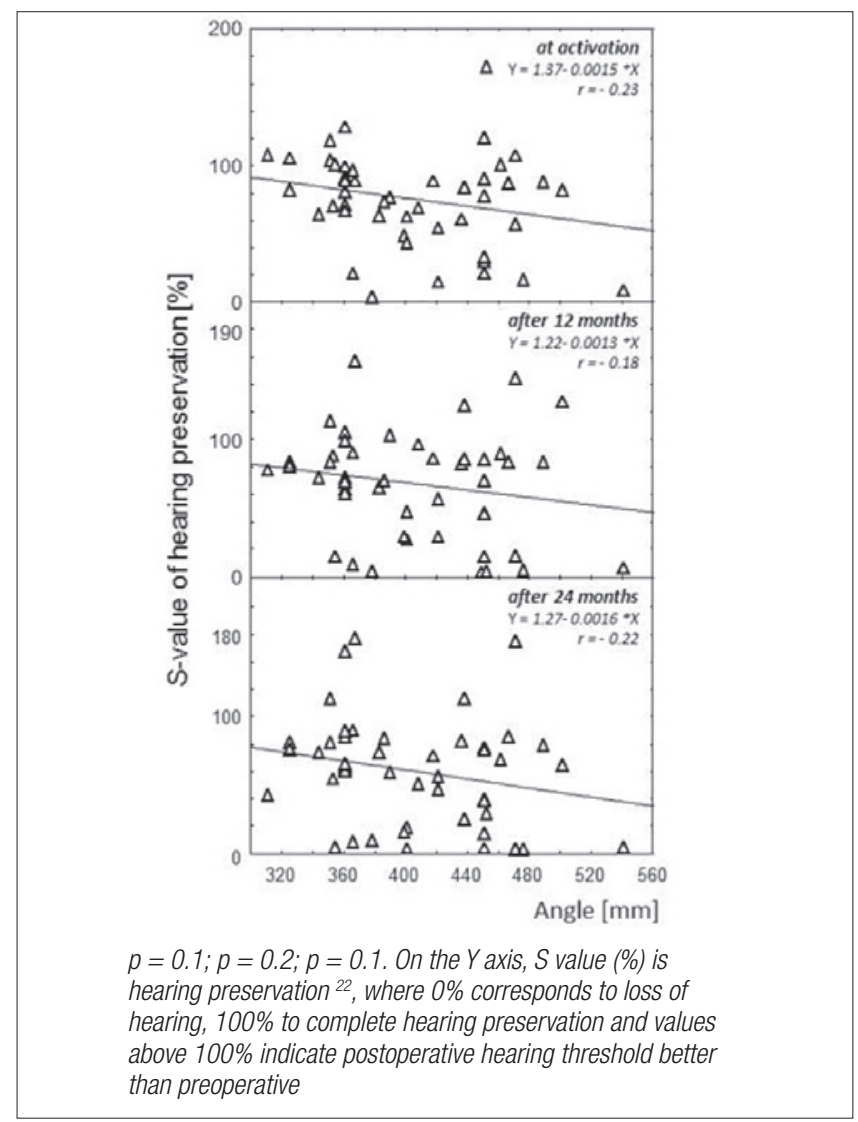

Fig. 2. Relation between hearing preservation calculated at activation and at 12 months and 24 months of follow-up vs. angular depth insertion (axis Y).

ample the largest in our study group with $\mathrm{A}=10.6 \mathrm{~mm}$ and $\mathrm{CDL}=40.65 \mathrm{~mm}$, an insertion to the depth of $20 \mathrm{~mm}$ would most probably not reach $360^{\circ}$, as it does in a medium sized cochlea ${ }^{18}$.
Referring to Greenwood's equation describing the frequency distribution along the organ of Corti, a proportion between the cochlear duct length and the linear position of electrode enables calculating the frequency at a furthest point of a specific electrode array penetration into the scala tympani ${ }^{12} 27$. According to our hypothesis, this information should help to avoid insertions that are too deep, which might cause low frequency hearing loss ${ }^{17-19}$. It might also be of considerable help in cases of preserved hearing in electro-acoustic stimulation, where precise estimation of a particular frequency is needed ${ }^{16}$. The first condition mentioned above is epitomised by the relation between HP rate and intrasurgical estimation of array insertion depth (Fig. 3), The second condition describes the relation between HP rate and proportion of cochlear duct length for the CI422 array (CDLCI422) and the intraoperatively estimated electrode insertion depth. We did not find this relationship to be statistically significant (Fig. 4). However, intraoperative estimation of insertion depth can be encumbered with errors resulting from such real life surgical situations such as a shortcut in the proximal part of basal turn or folding of an electrode tip ${ }^{28}{ }^{29}$. This is also suggested by the results published by Franke-Trieger et al. who reported $14 \%$ of cases falling outside the recommended depth in CT evaluation ${ }^{27}$.

In addition, Hassepass et al. ${ }^{4}$ performed similar measurements in their study of intraoperatively approximated insertions of $22 \mathrm{~mm}$. They reported mean postoperatively radiologically estimated insertion depth of $21.5 \mathrm{~mm}$. However, they did not report the nominal values of ranges of linear insertion. For this reason, we introduced a mathematical calculation of the LCI422 variable based on a value of angle of insertion and cochlea size, according to Alexiades ${ }^{26}$. Herein, insertions rated as $20 \mathrm{~mm}$ resulted with $21.4 \mathrm{~mm}$ (SD 1.0) in calculations based on radiological measurement and inser-

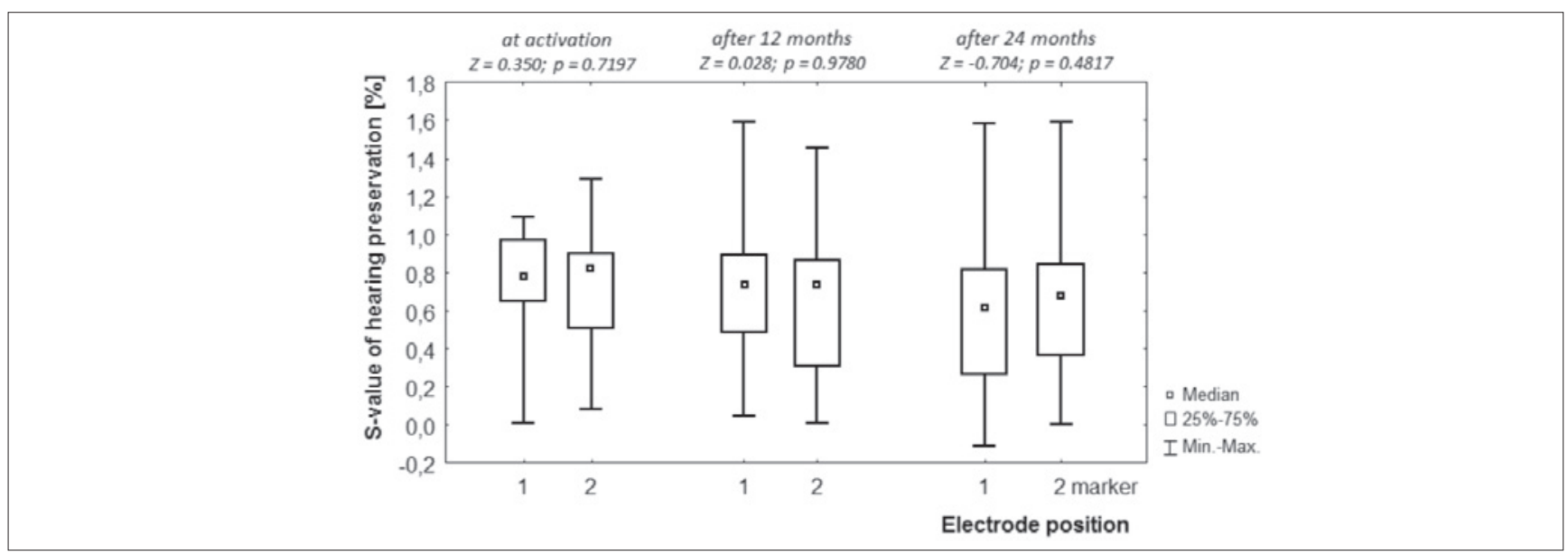

Fig. 3. Condition 1 . S value of hearing preservation during follow-up is not significantly related to intraoperatively estimated insertion depth of electrode array. 


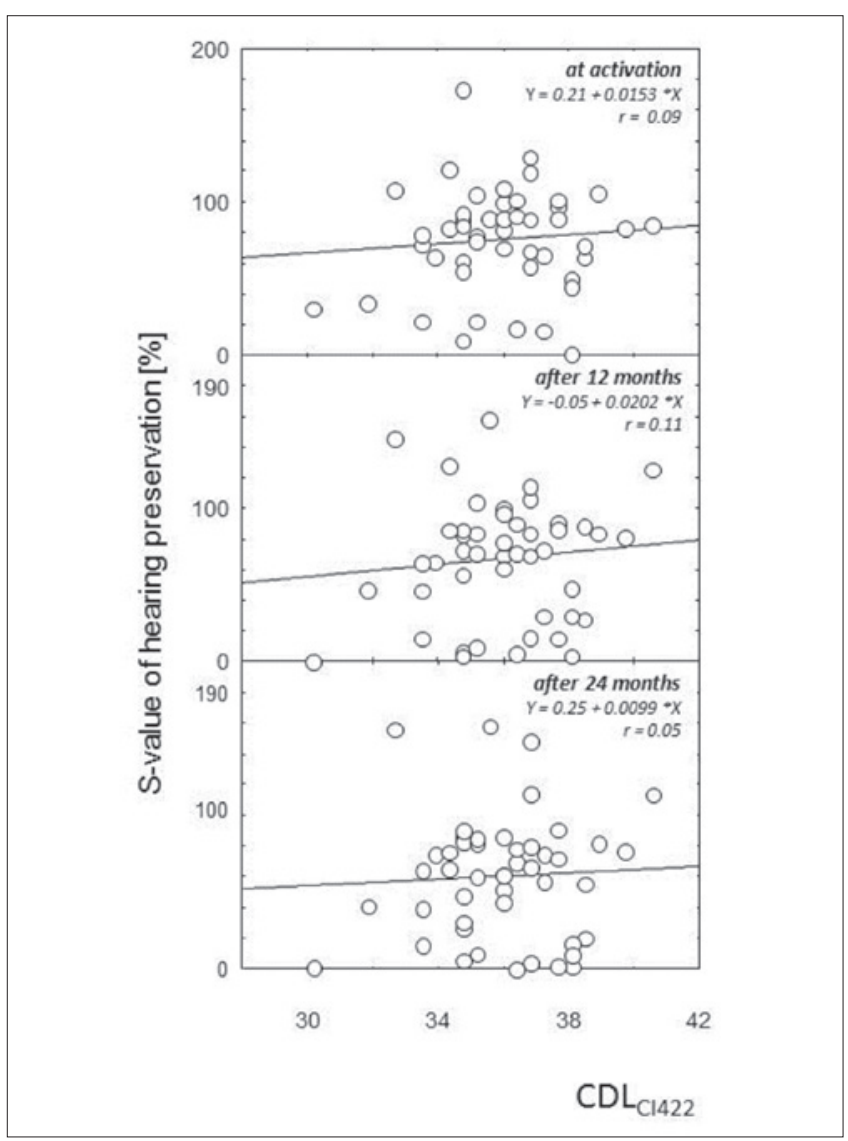

Fig. 4. Condition 2. Proportion of CDL Cl422 to intraoperatively estimated insertion depth of electrode array does not significantly influence $S$ value of $\mathrm{HP}$ during follow-up. The $Y$ axis is hearing preservation (S), and the $X$ axis is cochlear duct length for $\mathrm{Cl} 422$ electrode in $\mathrm{mm}$. Each dot represents an individual patient.

tions rated as $25 \mathrm{~mm}$ resulted with $23.1 \mathrm{~mm}$ (SD 1.8). The L CI422 /CDL CI422 proportion is independent of cochlea size, and is an individual measure of cochlear coverage. Cochlear coverage calculated based on the L CI422/CDL CI422 did not differ significantly from that calculated based on the CDL CI422 and intraoperative estimation. We did not find any significant difference between the HP and L CI422 /CDL CI422 across the study group (Fig. 5).

These relations have reference to our hypothesis, namely that HP rates in these conditions are not significantly different from one another. This does not corroborate our assumption that the preoperative measurement of cochlea size would increase the chances of high $\mathrm{S}$ value of HP.

A few cases where at activation we observed a minimal HP, although not complete hearing loss, were related to deep $\left(540^{\circ}\right.$ or $\left.450^{\circ}\right)$ insertions. These cases slip out of the general tendency. Radiological evaluation of the electrode array did not reveal array dislocation in any case.

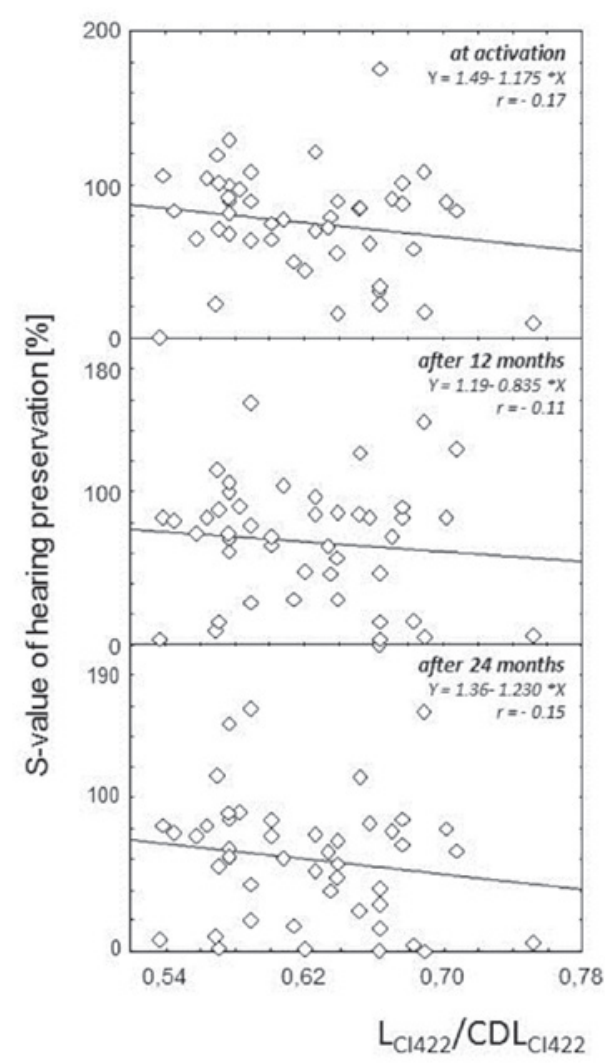

Fig. 5. Condition 2. CDL Cl422/LCl422 does not have a significant influence on $\mathrm{S}$ value of HP during follow-up. The $Y$ axis is hearing preservation $(\mathrm{S})$, and the $\mathrm{X}$ axis is a quotient of $\mathrm{Cl} 422$ electrode length divided by individual cochlear duct length for $\mathrm{Cl} 422$ electrode. Each dot represents an individual patient.

This result is in line with those reported by other authors. Erixson et al. in a study involving 21 patients implanted with Med-El electrodes found no significant relation between the HP rate and insertion angle or insertion depth ${ }^{17}$. In their investigation, the two deepest insertions of $540^{\circ}$ had also completely lost their hearing, although their measured linear insertions did not exceed $23.5 \mathrm{~mm}$ - pointing towards a conclusion that the risk of hearing loss is higher in a smaller cochleae -. A similar observation was reported by Fraysse in a study of 27 adults implanted with perimodiolar electrodes through a cochleostomy approach. Although in their estimation of the insertion depth angle they did not differentiate between a perimodiolar position of array and a lateral wall array, and for that reason is less precise, the general tendency is analogous to that observed in our study group. In their study, the greatest insertion angle was $435^{\circ}$ and the postoperative increase of hearing threshold 
for $250-500 \mathrm{~Hz}$ averaged over $50 \mathrm{~dB}{ }^{18}$. It also suggests that future analyses should investigate electrode types and hearing thresholds ${ }^{30} 31$.

Another important factor is the age of a patient ${ }^{32}$. In an elderly population, deeper insertions should possibly be recommended, including patients with a substantial preoperative hearing suitable for preservation ${ }^{33}$.

\section{Conclusions}

On the basis of our results we conclude that preoperative measurements of cochlea size and application of specific calculated parameters such as cochlear duct length, angle of insertion and linear insertion depth do not seem to effectively increase the probability of hearing preservation in cochlear implantation when using slim straight arrays and the round window surgical approach.

Although radiological evaluation of electrode position, including linear insertion depth, appears to provide more precise information compared to the intraoperative evaluation of electrode position, this measurement does not assure a successful and safe implantation in terms of preservation of low frequency hearing. Poor results of hearing preservation in some cases of deep insertion angles cannot be explained entirely by the electrode position.

\section{Conflict of interest statement}

None declared.

\section{References}

1 Rader T, Bohnert A, Matthias, et al. Hearing preservation in children with electric-acoustic stimulation after cochlear implantation: Outcome after electrode insertion with minimal insertion trauma. HNO 2018 Aug 21. doi: 10.1007/s00106-018-0532-3 [Epub ahead of print].

2 Skarzynski H, Lorens A, Dziendziel B, et al. Electro-Natural Stimulation (ENS) in partial deafness treatment: paediatric case series. Otol Neurotol 2018 in press.

3 Skarzynski H, Lorens A, Piotrowska A, et al. Preservation of low frequency hearing in partial deafness cochlear implantation (PDCI) using the round window surgical approach. Acta Otolaryngol (Stockh) 2007;127:41-8.

4 Hassepass F, Aschendorff A, Bulla S, et al. Radiologic results and hearing preservation with a straight narrow electrode via round window versus cochleostomy approach at initial activation. Otol Neurotol 2015;36:993-1000.

5 Causon A, Verschuur C, Newman TA. A retrospective analysis of the contribution of reported factors in cochlear implantation on hearing preservation outcomes. Otol Neurotol 2015;36:1137-45.

6 Kós M-I, Boëx C, Sigrist A, et al. Measurements of elec- trode position inside the cochlea for different cochlear implant systems. Acta Otolaryngol (Stockh) 2005;125:474-80.

7 Franke-Trieger A, Jolly C, Darbinjan A, et al. Insertion depth angles of cochlear implant arrays with varying length: a temporal bone study. Otol Neurotol 2014;35:58-63.

8 Pelliccia P, Venail F, Bonafé A, et al. Cochlea size variability and implications in clinical practice. Acta Otorhinolaryngol Ital 2014;34:42-9.

9 Trieger A, Schulze A, Schneider M, et al. In vivo measurements of the insertion depth of cochlear implant arrays using flat-panel volume computed tomography. Otol Neurotol 2011;32:152-7.

10 De Seta D, Mancini P, Russo FY, et al. 3D curved multiplanar cone beam CT reconstruction for intracochlear position assessment of straight electrodes array. A temporal bone and clinical study. Acta Otorhinolaryngol Ital 2016;36:499-505.

11 Diogo I, Walliczeck U, Taube J, et al. Possibility of differentiation of cochlear electrodes in radiological measurements of the intracochlear and chorda-facial angle position. Acta Otorhinolaryngol Ital 2016;36:310-6.

12 Stakhovskaya O, Sridhar D, Bonham BH, et al. Frequency map for the human cochlear spiral ganglion: implications for cochlear implants. J Assoc Res Otolaryngol 2007;8:220-33.

13 Erixon E, Högstorp H, Wadin K, et al. Variational anatomy of the human cochlea: implications for cochlear implantation. Otol Neurotol 2009;30:14-22.

14 Escudé B, James C, Deguine O, et al. The size of the cochlea and predictions of insertion depth angles for cochlear implant electrodes. Audiol Neurootol 2006 (Suppl 11);1:27-33.

15 Kawano A, Seldon HL, Clark GM. Computer-aided threedimensional reconstruction in human cochlear maps: measurement of the lengths of organ of Corti, outer wall, inner wall, and Rosenthal's canal. Ann Otol Rhinol Laryngol 1996;105:701-9.

16 Skarzynski H, Lorens A, Piotrowska A, et al. Hearing preservation in partial deafness treatment. Med Sci Monit 2010;16:555-62.

17 James C, Albegger K, Battmer R, et al. Preservation of residual hearing with cochlear implantation: how and why. Acta Otolaryngol (Stockh) 2005;125:481-91.

18 Fraysse B, Macías AR, Sterkers O, et al. Residual hearing conservation and electroacoustic stimulation with the nucleus 24 contour advance cochlear implant. Otol Neurotol 2006;27:624-33.

19 Erixon E, Köbler S, Rask-Andersen H. Cochlear implantation and hearing preservation: results in 21 consecutively operated patients using the round window approach. Acta Otolaryngol (Stockh) 2012;132:923-31.

20 Skarzynski H, van de Heyning P, Agrawal S, et al. Towards a consensus on a hearing preservation classification system. Acta Otolaryngol Suppl 2013;(564):3-13.

21 Skarzynski H, Matusiak M, Piotrowska A, et al. Surgi- 
cal techniques in partial deafness treatment. J Hear Sci 2012;2:9-13.

22 Tyler RS, Wood EJ. A comparison of manual methods for measuring hearing levels. Int J Audiol 1980;19:316-29.

${ }_{23} \mathrm{Xu} \mathrm{J}, \mathrm{Xu} \mathrm{SA}$, Cohen LT, et al. Cochlear view: postoperative radiography for cochlear implantation. Am J Otol 2000;21:49-56.

24 Verbist BM, Skinner MW, Cohen LT, et al. Consensus panel on a cochlear coordinate system applicable in histologic, physiologic, and radiologic studies of the human cochlea. Otol Neurotol 2010;31:722-30.

25 Cohen LT, Xu J, Xu SA, et al. Improved and simplified methods for specifying positions of the electrode bands of a cochlear implant array. Am J Otol 1996;17:859-65.

26 Alexiades G, Dhanasingh A, Jolly C. Method to estimate the complete and two-turn cochlear duct length. Otol Neurotol 2015;36:904-7.

27 Greenwood DD. A cochlear frequency-position function for several species - 29 years later. J Acoust Soc Am 1990;87:2592-605.
28 Sipari S, Iso-Mustajärvi M, Matikka H, et al. Cochlear implantation with a novel long straight electrode: the insertion results evaluated by imaging and histology in human temporal bones. Otol Neurotol 2018;39:e784-e793.

29 Skarzynski H, Lorens A, Matusiak M, et al. Partial deafness treatment with the nucleus straight research array cochlear implant. Audiol Neurootol 2012;17:82-91.

30 Lee A, Jiang D, McLaren S, et al. Electric acoustic stimulation of the auditory system: experience and results of ten patients using MED-EL's M and FlexEAS electrodes. Clin Otolaryngol 2010;35:190-7.

31 Skarzynski PH, Olszewski L, Lorens A, et al. Cochlear implantation in the elderly. Audiol Neurootol 2014 (Suppl 19);1:33-5.

32 Skarzynski H, Lorens A, Dziendziel B, et al. Expanding pediatric cochlear implant candidacy: a case study of electro-natural stimulation (ENS) in partial deafness treatment. Int J Pediatr Otorhinolaryngol 2015;79:1896-900.

33 Ciorba A, Hatzopoulos S, Bianchini C, et al. Genetics of presbycusis and presbystasis. Int $\mathrm{J}$ Immunopathol Pharmacol 2015;28:29-35.

Received: January 1, 2017- Accepted: March 14, 2018

Address for correspondence: Piotr Henryk Skarzynski, Heart Failure and Cardiac Rehabilitation Department Medical University of Warsaw, Poland Tel. +48 22 3560486. Fax +48 22 3560367. E-mail: p.skarzynski@inz.waw.pl 